\title{
Effect of High Concentrations of Alkaline Mediums in Wet Processing on
}

\author{
Cellulosic Materials \\ تأثير المعالجات الثرطبة على الألياف السليلوزية في الأوساط التاعبة ذات التركيزات العائية \\ By \\ A. R. Ramadan*, A. A. Hebeish**, A. M. El-Hossini*, and I. M. Rakha* \\ *Textile Engineering Department, Mansoura University. \\ ** National Research Centre, Textile Research division, Dokki, Cairo, Egypt
}

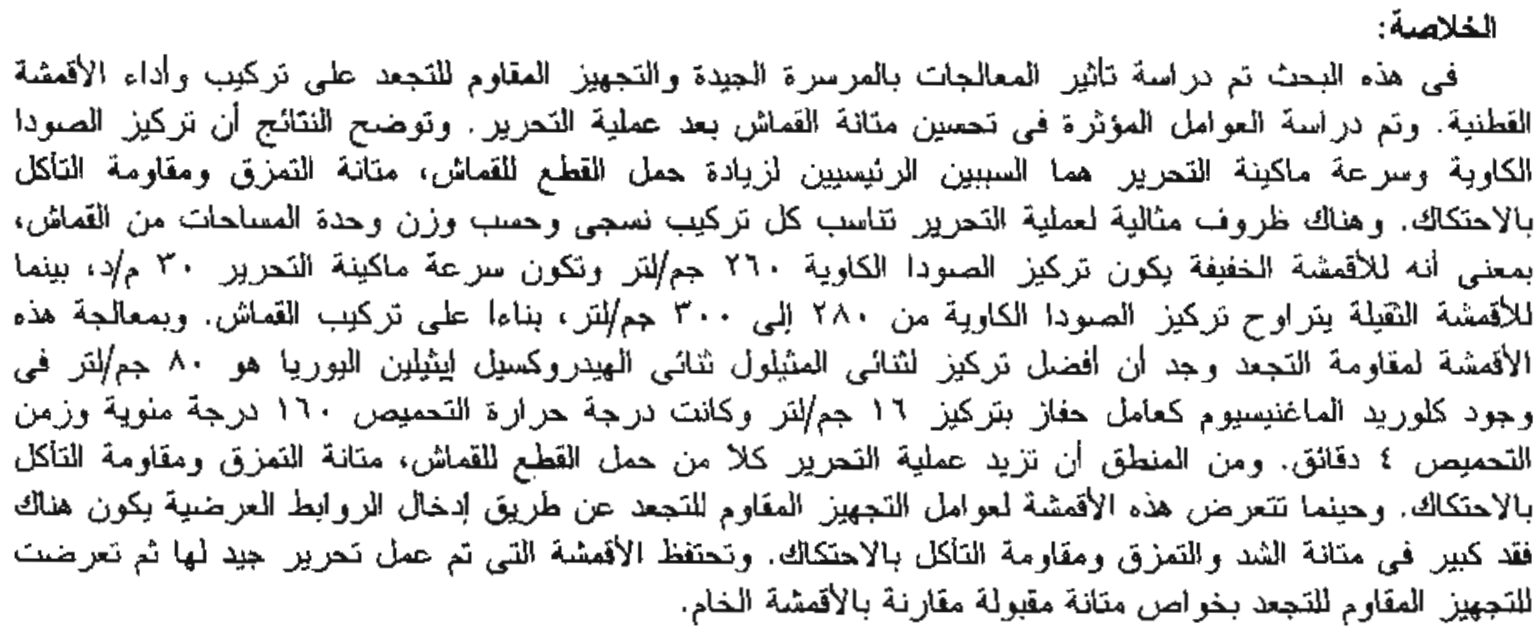

Abstract:

In this research, a study of the effect of good mercerization and cross-linking treatments on cotton fabrics structurc and performance was made. The factors affecting enhancement of fabric strength after mercerization were investigated. The results showed that the caustic soda $(\mathrm{NaOH})$ concentration and mercerizing machine speed are the main causes of increasing the fabric breaking load, tear strength and abrasion resistance. Also, for every fabric structure and weight per unit area there are optimum conditions of mercerization; i.e. for light fabrics the $\mathrm{NaOH}$ concentration was $260 \mathrm{~g} / \mathrm{lit}$ and the mercerizing machine speed was $30 \mathrm{~m} / \mathrm{min}$, while for heavy fabrics the $\mathrm{NaOH}$ concentration ranges from 280 to $300 \mathrm{~g} / \mathrm{lit}$, depending on the fabric structure. When these fabrics were subjected to cross-linking treatments, the best DMDHEU concentration was $80 \mathrm{~g} /$ lit in the presence of magnesium chloride $\left(\mathrm{Mg} \mathrm{Cl}_{2}, 6 \mathrm{H}_{2} \mathrm{O}\right)$ as a catalyst at $16 \mathrm{~g} / \mathrm{lit}$, the curing temperature was $160^{\circ} \mathrm{C}$ and the curing time was 4 minutes. Logically, mercerization improves fabric breaking load, tear strength and abrasion resistance by virtue of the favorable effect of mercerization on the degree of orientation and uniformity of cotton structure. When these fabrics were subjected to cross-linking treatment; there was a considerable loss in the tensile, tear strength and abrasion resistance. The good mercerized then cross-linked fabrics retained accepted strength properties compared to the raw fabrics.

\section{Keywords:}

Mercerization, Resin finishing, Mechanical properties.

\section{Introduction:}

Resin or wrinkle free finishing is widely used in the textile industry to impart wrinkle resistance to cotton fabrics and garments. Considerable loss in strength and abrasion resistance of the finished fabrics has been a major concern for the industry. Enhancing dimensional stability and wrinkle resistance with resin finishing of cotton has constantly been correlated with lower abrasion resistance and tear strength. The strength of the fiber depends on how much the cross-linked chains can still be mutually displaced under tension in order to sufficiently resist the applied load. The rigid cross-links that 
are formed with the DMDHEU obviously prevent the redistribution of stress by preventing segmental movement within the fiber microstructure. The cross-linking of cellulose molecules with these relatively rigid cross-links causes stiffening of the cellulosic macromolecular network and fiber embitterment, thus dropping the mechanical strength of the treated cotton fabrics. These same mechanisms are responsible for reduced mechanical properties of the fiber surface, thus leading to strength loss. Fiber surface property alteration, such as through the use of softeners, has been shown to play an important task in minimizing strength loss ${ }^{[1-5]}$. Good mercerization enbances fabric tensile, tear strength and abrasion resistance. This could be associated with the higher degree of molecular orientation of cotton during mercerization under tension; the latter is logically increases by increasing the machine speed. It is understandable that the enhancement in the breaking load of cotton fabric after mercerization is essentially due to higher degree of molecular orientation along with more uniform structure of cotton. The decrease in breaking load expected form decreasing the crystalline / amorphous ratio by mercerization is prevailed over by greater orientation and uniformity of the cotton structure.

\section{Review of literature:}

Weilin Xu performed a treatment on cotton fabrics at different curing temperatures with different concentrations of 1,2,3,4-butanetetracarboxylic acid (BTCA) catalyzed with sodium hypophosphite (SHP). Strength retention and winkle recovery angle (WRA) were tested, and the results show that high curing temperature and high BTCA concentration will reduce fabric strength and increase WRA ${ }^{[6]}$. Avinash subjected fabric samples to $\mathrm{NaOH}$ and $\mathrm{KOH}$ pretreatments then resin finishing. The treated samples were tested to determine the influence of alkali pretreatments on the tenacity, abrasion resistance, and crease recovery of resin-finished lyocell. Alkali pretreatments resulted in a higher surface concentration of the cross-linking reagent in fabrics, leading to lowered crease recovery and abrasion resistance. The pretreatments also exerted a deleterious influence on the tensile sirength in resinfinished samples. However, the differential distribution of cross-linking reagent within the textile structure did not appear to be the only factor responsible for the changes observed in substrate properties; other factors also appear to be responsible for the results observed ${ }^{[7]}$. Buschle used both sodium hydroxide solution of mercerizing strength and anhydrous methylamine for enhancing the reactivity of cotton cellulose. Favorable results are achieved by maintaining the fiber material in the never-dried state after the swelling treatment. The tensile properties of the acetylated products of low acetyl content are considerably improved if acetylation is preceded by mercerization with subsequent solvent exchange, and less so if it is preceded by methylamine followed by solvent exchange. Incorporation of acetyl groups significantly enhances the breaking strength and extensibility of mercerized solvent-washed materials ${ }^{[8]}$. Weilin Xu made a treatment on cotton fibers and their fabric with BTCA with the catalyst SHP at different concentrations of treating agent and different curing temperatures. Results show that low curing temperatures and low agent concentrations have a slight effect on the reduction of crystallinity and crystallite size, but when the curing temperature is higher than $180^{\circ} \mathrm{C}$ and the BTCA concentration is higher than $6 \%$, crystallite size and crystallinity decrease significantly. This may be ascribed to the acidic erosion of the surface of the crystals at high temperatures. An initial slight crystallinity loss induces high strength loss in the fabric. This is perhaps due to the initial slight reduction of crystallinity, which causes serious interfacial binding strength losses between the crystals and the amorphous regions ${ }^{[9]}$. 


\section{Experimental plan}

\subsection{Objectives:}

- To establish optimum conditions for mercerization and resin finishing treatments with respect to fabrics having different structures.

- To decrease the strength loss due to resin finishing.

\subsection{Raw Materials:}

a) Raw cotton fabrics with different structures such as plain weave $1 / 1$, twill weave $3 / 1$ and,

b) Bleached cotton fabrics with different structures, i.e. plain weave $1 / 1$, warp rep and twill weave, as shown in table (1).

Table (l) specifications of treated fabrics

\begin{tabular}{|c|c|c|c|c|c|c|}
\hline \multicolumn{6}{|c|}{ Fabrics Specifications } & \multirow[b]{2}{*}{$\begin{array}{c}\text { State of } \\
\text { mercerization }\end{array}$} \\
\hline $\begin{array}{l}\text { Fabric } \\
\text { structure }\end{array}$ & $\begin{array}{c}\text { Fabrte } \\
\text { state }\end{array}$ & $\begin{array}{l}\text { Fubric } \\
\text { width } \\
\text { (cm) }\end{array}$ & $\begin{array}{l}\text { Yarns } \\
\text { count } \\
\text { (Ne) }\end{array}$ & $\begin{array}{c}\text { Density } \\
\text { (ends* picks } \\
\text { /inch) }\end{array}$ & $\begin{array}{l}\text { Fabric } \\
\text { weight } \\
\left(\mathrm{g} / \mathrm{m}^{2}\right)\end{array}$ & \\
\hline Plain $1 / 1$ & Bleached & 160 & $30 * 30$ & $76 * 68$ & 123 & before \\
\hline Plain $1 / 1$ & Bleached & 145 & $30 * 30$ & $79 * 67$ & 118 & speed $50 \mathrm{~m} / \mathrm{min}$ \\
\hline Plain 1/1 & Bleached & 135 & $30 * 30$ & $81 * 66$ & 117 & speed $40 \mathrm{~m} / \mathrm{min}$ \\
\hline Plain $1 / t$ & Bleached & 130 & $30 * 30$ & $83 * 66$ & 118 & speed $30 \mathrm{~m} / \mathrm{min}$ \\
\hline Warp Rep & Bleached & 160 & $40 / 2 * 24$ & $82 * 52$ & 232 & before \\
\hline Warp Rep & Bleached & 145 & $40 / 2 * 24$ & $89 * 50$ & 208 & speed $40 \mathrm{~m} / \mathrm{min}$ \\
\hline Warp Rep & Bleached & 151 & $40 / 2 * 24$ & $87 \cdot 50$ & 205 & speed $30 \mathrm{~m} / \mathrm{min}$ \\
\hline Twil] $3 / 1$ & Raw & 174 & $20 * j 4$ & $105 * 54$ & 250 & before \\
\hline Twill $3 / 1$ & Raw & 150 & $20 * 14$ & $118 * 52$ & $2[8$ & speed $30 \mathrm{~m} / \mathrm{min}$ \\
\hline Twill $3 / 1$ & Bleached & 160 & $20 * 14$ & $107 * 54$ & 250 & before \\
\hline Twill 3/1 & Bleached & 145 & $20 * 14$ & $122 * 52$ & 222 & speed $30 \mathrm{~m} / \mathrm{min}$ \\
\hline
\end{tabular}

\subsection{Treatments:}

a) All the above fabrics were subjected to:

- Mercerization using different $\mathrm{NaOH}$ concentrations, namely, 220,240, 260, 280 $\mathrm{g} / \mathrm{lit}$ under the same conditions (mercerizing machine speed, fabric tension, rollers pressure and temperature).

- Mercerization using different mercerizing machine speeds: $20,30,40,50 \mathrm{~m} / \mathrm{min}$ under the same conditions, see table (2).

b) From mercerization tests, the good conditions for light fabrics were: $\mathrm{NaOH}$ concentration $260 \mathrm{~g} / \mathrm{lit}$ and the mercerizing machine speed $30 \mathrm{~m} / \mathrm{min}$, as shown in figures from (1) to (3).

c) These fabrics were then subjected to wrinkle recovery finishing using
DMDHEU at different concentrations: 40 , $60,80,100 \mathrm{~g} /$ lit in the presence of magnesium chloride $\left(\mathrm{Mg} \mathrm{Cl}_{2} .6 \mathrm{H}_{2} \mathrm{O}\right)$ as a catalyst at different concentrations, namely $8,12,16,20 \mathrm{~g} /$ lit along with fatty acids (non-ionic) at concentration $20 \mathrm{~g} / \mathrm{lit}$ and wetting agent. The fabrics were padded in a solution containing DMDHEU, catalyst and wetting agent to a wet pick ca $80 \%$, dried at ambient conditions then cured at $160^{\circ} \mathrm{C}$ for different curing times: $3,4,5$ minutes, as given in table (3).

d) Non mercerized fabric samples were subjected to cross-linking while other samples were mercerized then crosslinked. 
Table (2) mercerization treatments

\begin{tabular}{|c|c|c|c|c|c|}
\hline & Temp. & \multicolumn{4}{|c|}{ from 20 to $25^{\circ} \mathrm{C}$} \\
\hline 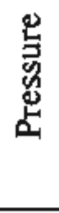 & $\begin{array}{r}\text { conc. } \\
\text { (g/lit) }\end{array}$ & 220 & 240 & 260 & 280 \\
\hline \multirow{4}{*}{ 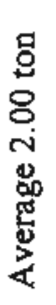 } & 20 & $x$ & $x$ & $x$ & $\mathrm{x}$ \\
\hline & 30 & $x$ & $\mathrm{x}$ & $x$ & $\mathrm{x}$ \\
\hline & 40 & $\mathrm{x}$ & $x$ & $\mathrm{x}$ & $x$ \\
\hline & 50 & $x$ & $x$ & $\mathrm{x}$ & $x$ \\
\hline
\end{tabular}

Table (3) cross-linking treatments

\begin{tabular}{|c|c|c|c|c|c|}
\hline & $\begin{array}{c}\text { Temperatur } \\
\mathrm{e}\end{array}$ & \multicolumn{4}{|c|}{$\begin{array}{l}\text { Curing temp. }=160 \\
{ }^{\circ} \mathrm{C}\end{array}$} \\
\hline $\begin{array}{l}\text { g } \\
\frac{y}{2} \\
\frac{y}{2}\end{array}$ & $\begin{array}{l}\text { DMDHEU } \\
\text { Curing } \\
\text { Time }\end{array}$ & 40 & 60 & 80 & 100 \\
\hline \multirow{3}{*}{ s } & 3 min & $x$ & $x$ & $x$ & $x$ \\
\hline & $4 \mathrm{~min}$ & $x$ & $\mathrm{x}$ & $x$ & $\mathrm{x}$ \\
\hline & 5 min & $x$ & $x$ & $x$ & $x$ \\
\hline
\end{tabular}

Testing:

The tests of breaking load, breaking elongation, tear strength and abrasion resistance were measured for all the following samples: un-mercerized fabrics, mercerized only, cross-linked only, mercerized then cross-linked fabrics.

\section{Test Methods:}

Breaking load and breaking elongation were measured using Tensolab cloth strength tester according to Egyptian Standard Specification 1506-1/2007 and tear strength using Elmendorf tear tester according to ASTM D1424 and fabric abrasion resistance using abrasion resistance tester according to ASTM D3884 - 09 .

\section{Results and Discussions:}

4.1 Effect of mercerization and crosslinking treatments on the fabric breaking load:

Figure (1) shows the effect of $\mathrm{NaOH}$ concentration on breaking load of plain weave $1 / 1$ in the warp direction. The percentage increase in breaking load ranges from 5.64 to $13.62 \%$ compared to non mercerized fabric. Enhancement in the breaking load by increasing the $\mathrm{NaOH}$ concentration up to a certain limit could be interpreted in terms of increasing the swelling action of $\mathrm{NaOH}$ on cotton. Once the proper swelling of cotton is attained, cotton undergoes changes in its fine physical structure which ultimately lead to better molecular orientation and uniformity of the structure. As a result, breaking load increases. The most constant breaking load values observed at higher $\mathrm{NaOH}$ concentrations (260 and $280 \mathrm{~g} /$ lit) suggest that the favorable swelling action by increasing $\mathrm{NaOH}$ concentration is outweighed by the very high viscosity of $\mathrm{NaOH}$ at higher concentrations i.e. 280 g/lit.

Figure (2) shows the effect of mercerization and cross-linking treatments on the fabric breaking load of plain weave $1 / 1$ in the warp direction. When these fabrics were subjected to mercerization with $\mathrm{NaOH}$ concentration $260 \mathrm{~g} / \mathrm{lit}$, the tensile strength (breaking load) increases by a percent ranges from 5.64 to $13.62 \%$. It is seen that the breaking load increases after mercerization regardless of the machine speed. However the latter exerts a remarkable positive effect on the breaking load. This could be associated with the higher degree of molecular orientation of cotton during mercerization under tension.

These fabrics were then subjected to cross-linking with DMDHEU concentration $80 \mathrm{~g} / \mathrm{lit}$ and the curing time was 4 minutes. Obviously, the breaking load decreases after resin finishing by a percent of 22.65 and $18.66 \%$ with respect to mercerized samples; as a result the mercerized then cross-linked samples lost a percent of its 
strength (compared to the non mercerized, non cross-linked samples) ranges from $20.23 \%$ to $7.59 \%$ at mercerizing machine speed $20 \mathrm{~m} / \mathrm{min}$ and $50 \mathrm{~m} / \mathrm{min}$ respectively.

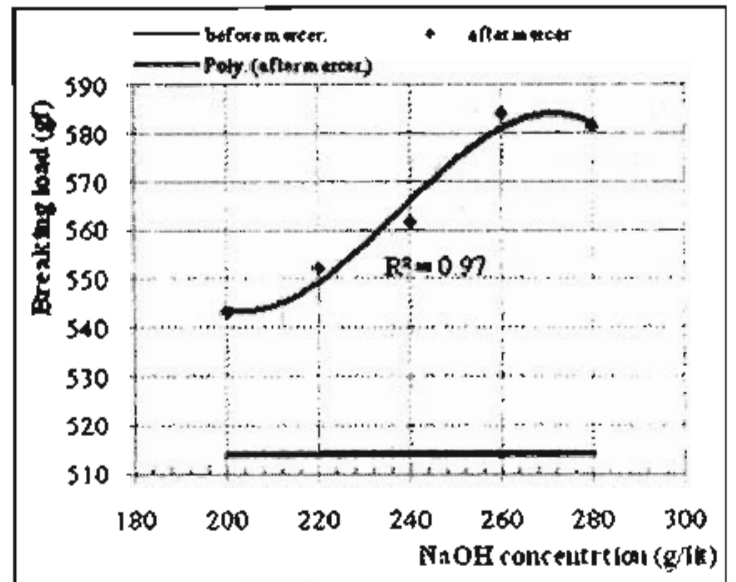

Fig. (I) Effect of NaOH concentration on fabric breaking load for plain weave $1 / 1$ in the warp direction.

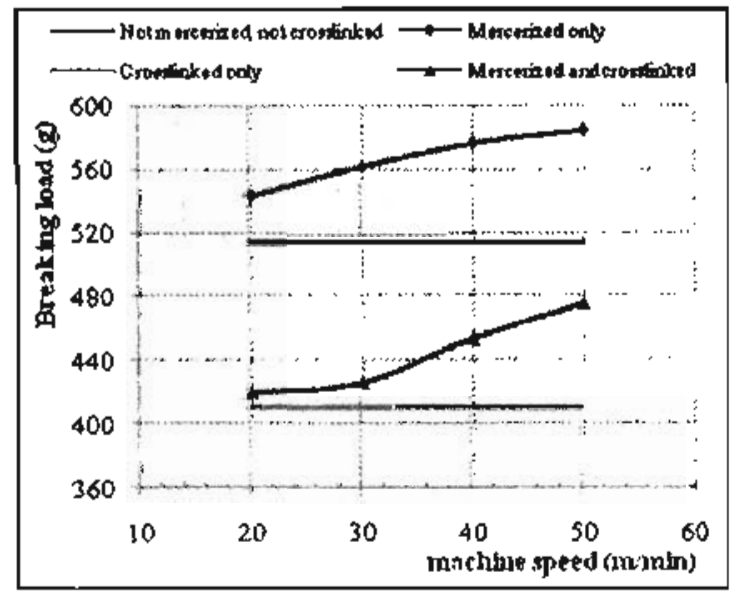

Fig. (2) Effect of mercerization and crosslinking trealments on fabric breaking load of plain weave I/I in the warp direction.

The same effect was found in the weft direction, i. e. mercerization improved the breaking load in the weft direction by a percent ranges from $7.03 \%$ to $11.18 \%$ with respect to non mercerized fabric, as shown in figure (3). Nevertheless, the breaking load in the weft direction decreases by increasing the speed of the machine, a point which is opposite to the warp direction. It seems very likely that increasing the speed of the machine during mercerization causes a sort of contraction and shrinkage of the weft yams in cotton fabric thereby detracting from their full benefit from the orientation of the cotton molecules.

When these fabrics were subjected to cross-linking, the breaking load decreases by about 21.73 to $23.33 \%$ at mercerizing machine speeds $20 \mathrm{~m} / \mathrm{min}$ and $50 \mathrm{~m} / \mathrm{min}$, respectively. As a result the mercerized then cross-linked samples lost a percent of its strength ranges from 11.87 to $17.27 \%$ compared to the non mercerized, non cross-linked samples, as machine speed ranges from 20 to $50 \mathrm{~m} / \mathrm{min}$.

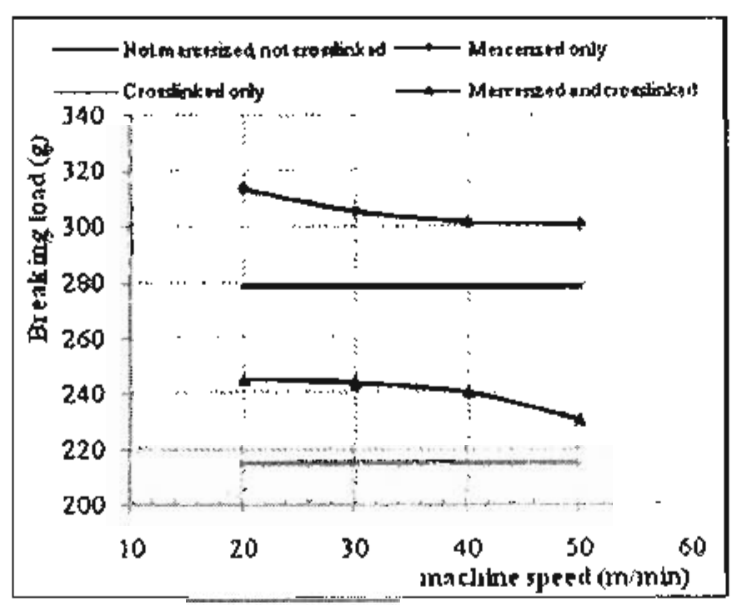

Fig. (3) Effect of mercerization and cross-

linking treatments on fabric breaking load of plain weave $1 / 1$ in the weff direction.

4.2 Effect of mercerization and crosslinking treatments on the fabric breaking elongation:

Figure (4) shows the effect of the speed of the mercerizing machine on fabric breaking elongation in the warp direction. The breaking elongation decreases from 9.58 to $15.96 \%$ by increasing the machine speed from 20 to $40 \mathrm{~m} / \mathrm{min}$, thereafter the decrease in breaking elongation was 10.64 $\%$ at machine speed of $50 \mathrm{~m} / \mathrm{min}$. This means that the decrease in elongation is observed only with the machine speeds 30 or $40 \mathrm{~m} / \mathrm{min}$. This may be interpreted in terms of changes in the micro structural features of the cotton cellulose and the influence of the caustic soda under different tensions as pointed out in case of the breaking load.

When these fabrics then subjected to cross-linking, the breaking elongation increases by a percent ranges from $0 \%$ to 
$2.53 \%$ at mercerizing machine speed 20 $\mathrm{m} / \mathrm{min}$ and $40 \mathrm{~m} / \mathrm{min}$ respectively. As a result the mercerized then cross-linked samples lost a percent of its breaking elongation ranges from $9.58 \%$ to $13.83 \%$ compared to the non mercerized, non cross-linked samples.

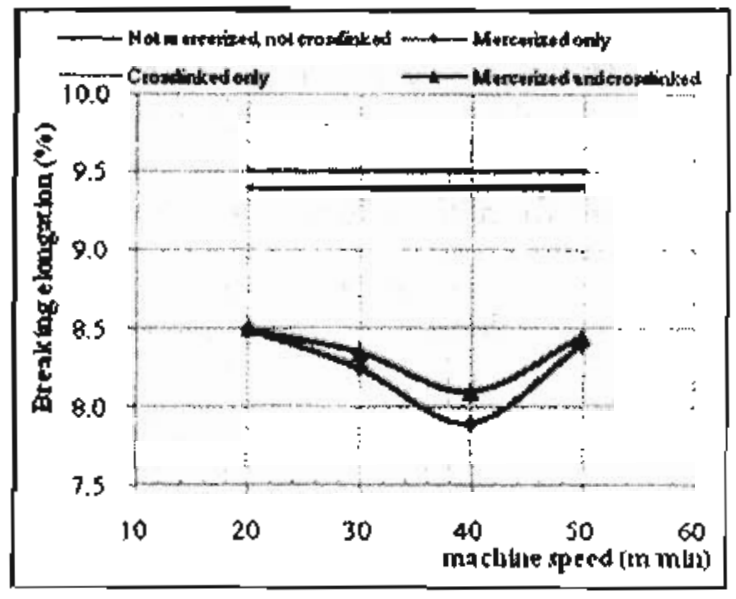

Fig. (4) Effect of mercerization and crosslinking on fabric breaking elongation of plain weave $1 / /$ in warp direction.

At the outset of this paragraph it is emphasized that fabric width before mercerization acquires a value of $160 \mathrm{~cm}$; this value decreases to $145 \mathrm{~cm}$ after mercerization. Figure (5) shows the relation between the breaking elongation of mercerized cotton fabric in the weft direction and the speed of the mercerizing machine. As is evident the breaking elongation decreases by increasing the mercerizing machine speed within the range studied, i.e. from 20 to $50 \mathrm{~m} / \mathrm{min}$ reasons cited above in case of the breaking load may be taken into consideration to account for this. On the other hand the breaking elongation values after mercerization are higher than the values before mercerization. The pre-mentioned shrinkage in the fabric width after mercerization together with changes in fine physical structure of cotton cellulose under the effect of $\mathrm{NaOH}$ which acquires mercerization strength would account for the outstanding increase in breaking elongation after mercerization regardless of the speed of the mercerizing machine. The breaking elongation increased after mercerization by a percent ranges from $11.58 \%$ to $16.17 \%$.

After cross-linking, the breaking elongation decreased by a percent ranges from $30.67 \%$ to $36.71 \%$ at mercerizing machine speed $20 \mathrm{~m} / \mathrm{min}$ and $50 \mathrm{~m} / \mathrm{min}$ respectively. As a result the mercerized then cross-linked samples lost a percent of its breaking elongation ranges from 19.49 $\%$ to $29.38 \%$ compared to the non mercerized, non cross-linked samples.

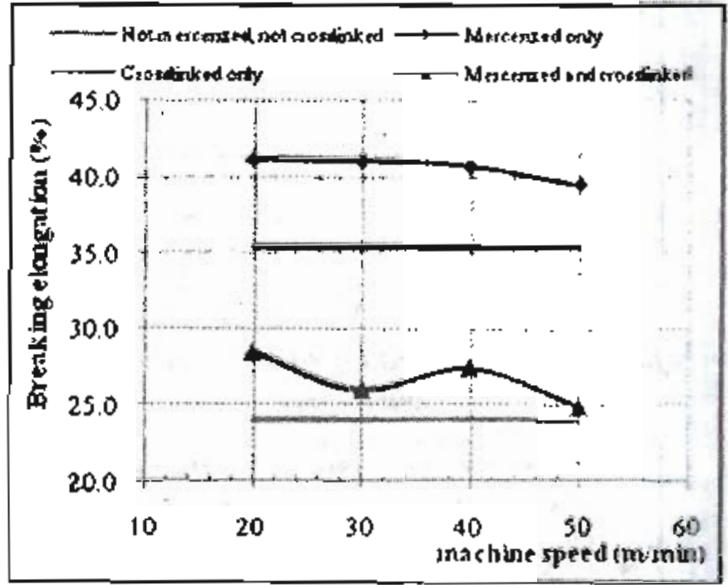

Fig. (5) Effect of mercerization and crosslinking on fabric breaking elongation of plain weave $I / I$ in the weft direction.

\subsection{Effect of resin finishing (cross- linking) on fabric tear:}

Figure (6) illustrates the effect of resin concentration on the fabric tear of non mercerized plain weave $(1 / 1)$ in the warp direction. Results show that the fabric tear decreases by increasing the resin concentration, also its value is lower than the raw samples. The percentage decrease in fabric tear ranges from 0 to $2.94 \%$. The proper resin concentration is $40 \mathrm{~g} / \mathrm{lit}$ and the best curing time for the treated fabrics is $4 \mathrm{~min}$, where for resin concentration 40 g/lit the proper curing time was $3 \mathrm{~min}$ and for $80 \mathrm{~g} /$ lit the proper time was $4 \mathrm{~min}$.

Similarly, the effect of resin concentration on the fabric tear of bleached and mercerized plain weave (1/1) in the warp direction is shown in figure (7). The fabric tear decreases as increasing the resin concentration; at all cases its value is lower than the mercerized only 
samples. The percentage decrease in fabric tear ranges from $2.63 \%$ to $5.26 \%$. The best resin concentration is $40 \mathrm{~g} / \mathrm{lit}$ and the best curing time is $3 \mathrm{~min}$.

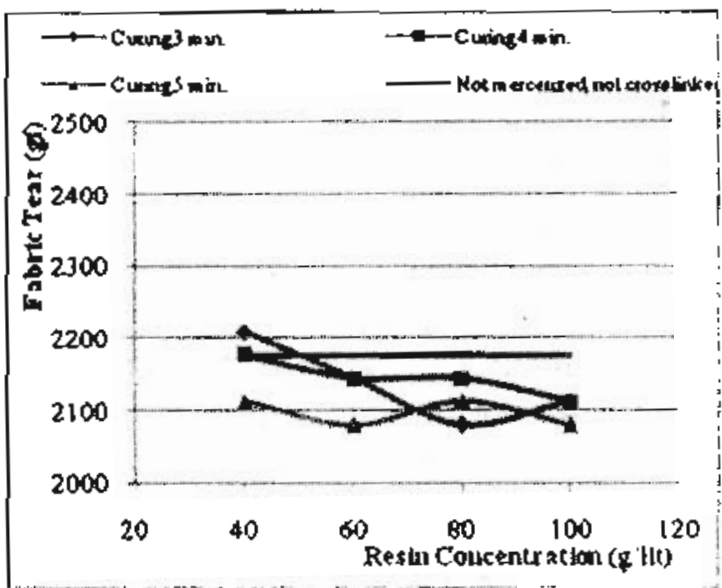

Fig. (6) Effect of resin concentration on fabric tear of non mercerized bleached plain weave in the warp direction

The loss in fabric tear after crosslinking treatment may be due to both the cross-linking of cellulose and the degradation of cellulose caused by the catalyst. The magnitude of fabric strength loss is affected also by the temperature, time, and concentration of the catalyst.

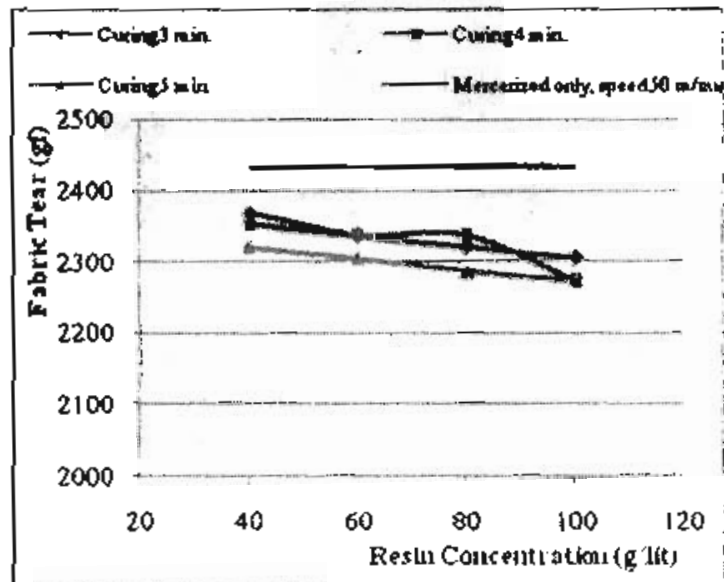

Fig. (7) Effect of resin concentration on fabric tear of mercerized plain weave in the warp direction, mercerizing machine speed $50 \mathrm{~m} / \mathrm{min}$.

The action is similar in the weft direction i.e. the fabric tear decreases as increasing the resin concentration; at all cases its value is lower than the mercerized only samples. Figure (8) shows the effect of resin concentration on the fabric tear in the weft direction of plain weave (1/1) bleached cotton fabric before mercerization (non mercerized fabric).

It is cleared that: The percentage decrease in fabric tear ranges from $3.33 \%$ to $5 \%$. The best resin concentration is 40 $g /$ lit and the best curing time for the treated fabrics is 3 min.

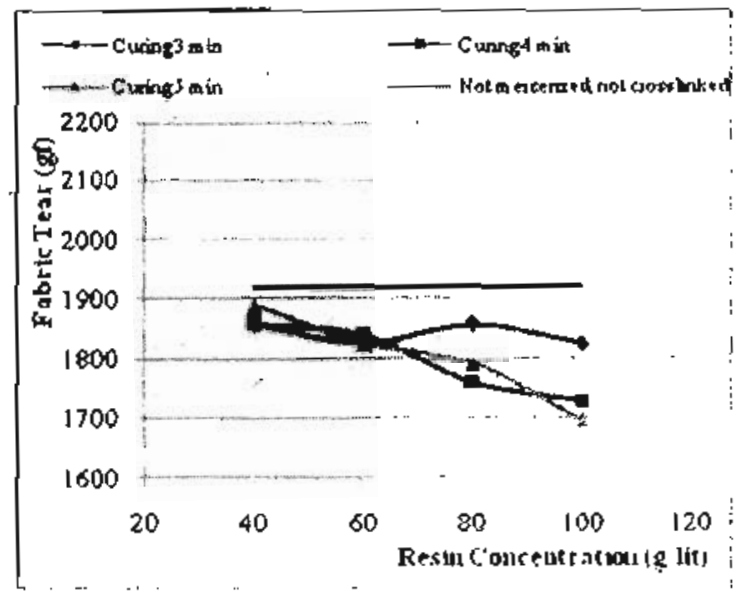

Fig. (8) Effect of resin concentration on fabric tear of non mercerized bleached plain weave in the weft direction

Figure (9) shows that the fabric tear decreases as increasing the resin concentration, at all cases its value is lower than the mercerized only samples. The percentage decrease in fabric tear ranges from $2.99 \%$ to $7.46 \%$. The best resin concentration is $40 \mathrm{~g} /$ lit. The best curing time for the treated fabrics is $4 \mathrm{~min}$.

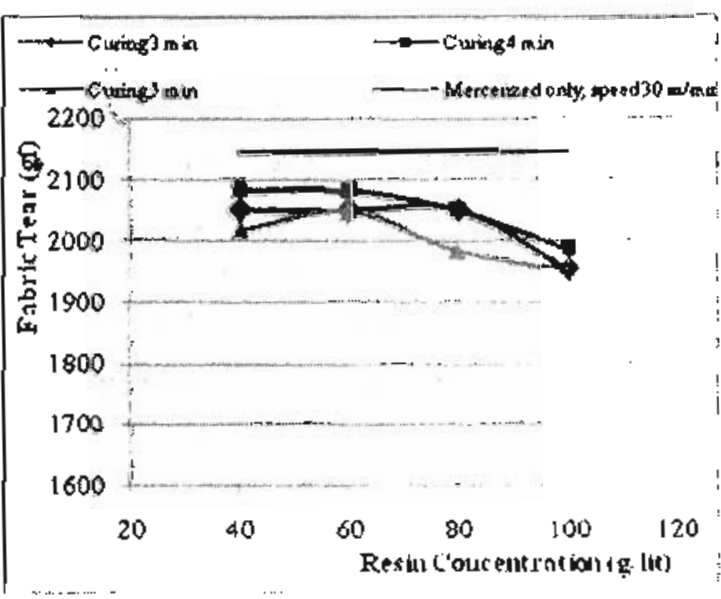

Fig. (9) Effect of resin concentration on fabric tear of mercerized plain weove in the wen direction, mercerizing machine speed $30 \mathrm{~m} / \mathrm{min}$. 
Figure (10) illustrates the effect of resin concentration on the fabric tear of mercerized and non mercerized plain weave (1/1) in the warp direction, the fabric tear decreases as increasing the resin concentration, at all cases its values for mercerized samples are tigher than the non mercerized samples. The best resin concentration is $40 \mathrm{~g} /$ lit. The best mercerizing machine speed is $50 \mathrm{~m} / \mathrm{min}$.

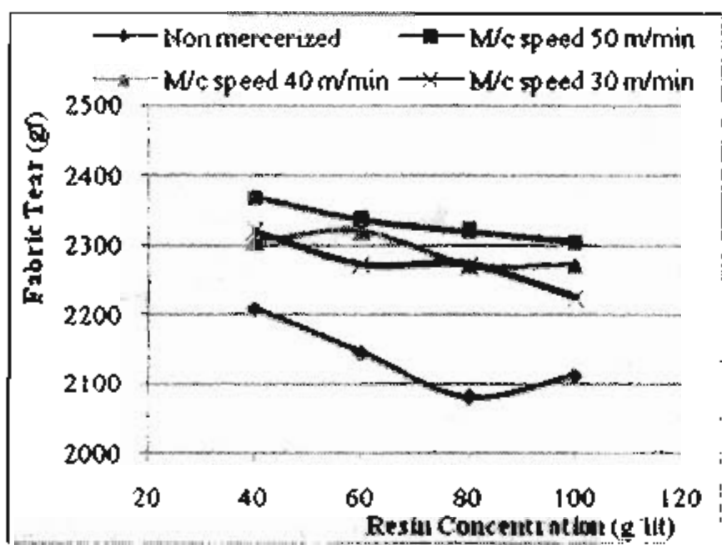

Fig. (10) Effect of resin concentration of mercerized and non mercerized collon fabrics on fabric tear in the warp direction.

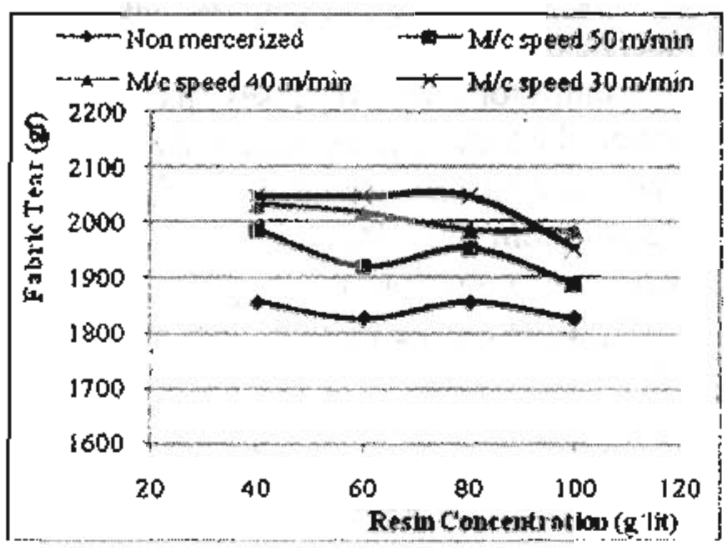

Fig. (11) Effect of resin concentration of mercerized and non mercerized cotton fabrics on fabric tear in the weft direction.

Similarly, figure (11) illustrates the effect of resin concentration on the fabric tear of mercerized and non mercerized plain weave (1/1) in the weft direction, the fabric tear decreases as increasing the resin concentration, at all cases its values for mercerized samples are higher than the non mercerized samples. The best resin concentration is $40 \mathrm{~g} / \mathrm{lit}$. The best mercerizing machine speed is $30 \mathrm{~m} / \mathrm{min}$.

\subsection{Effect of fabric structure on the fabric tear:}

Figure (12) shows the effect of mercerization and cross-linking on the fabric tear of plain weave $1 / 1$ raw fabric in the warp direction. Results obtained provide that:

- The fabric tear increased after mercerization by about $7.69 \%$ then decreased after cross linking by about $7.69 \%, 19.15 \%$ and $19.15 \%$ for curing times $3 \mathrm{~min}, 4 \mathrm{~min}$ and 5 $\mathrm{min}$ respectively.

- The best curing time for the treated fabrics is 3 min.

- The fabric tear for the mercerized then cross-linked sample is the same as the raw fabric, for curing time 3 min only.

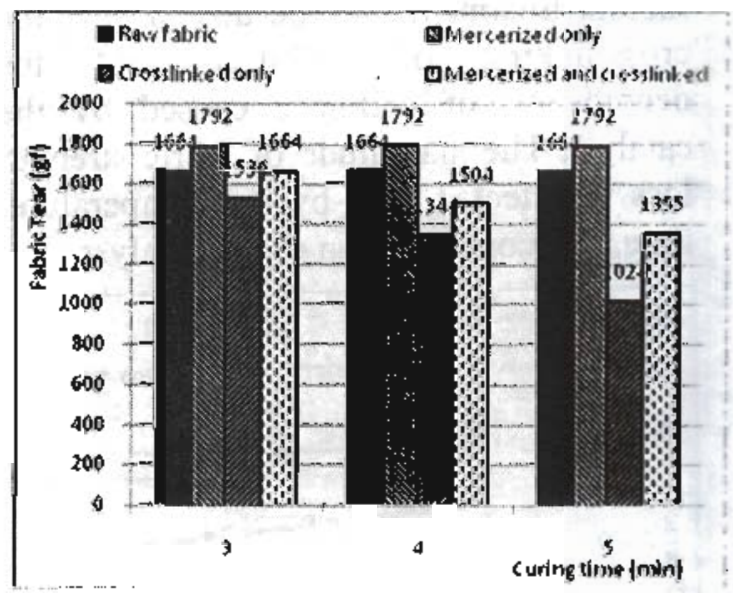

Fig. (12) Effect of mercerization and crosslinking treatments on the fabric tear of plain weave 1/I raw fabric in the warp direction.

Figure (13) shows the effect of mercerization and cross-linking agents on the fabric tear of plain weave $1 / 1$ raw fabric in the weft direction. As a result fabric tear decreased after mercerization by about $9.00 \%$ then decreased after cross linking by about $5.50 \%, 7.69 \%$ and $18.68 \%$ for curing times 3 $\mathrm{min}, 4 \mathrm{~min}$ and $5 \mathrm{~min}$ respectively. The best curing time for the treated fabrics is $3 \mathrm{~min}$. The fabric tear for the cross-linked sample is lower than the raw fabric by about $14 \%$. 


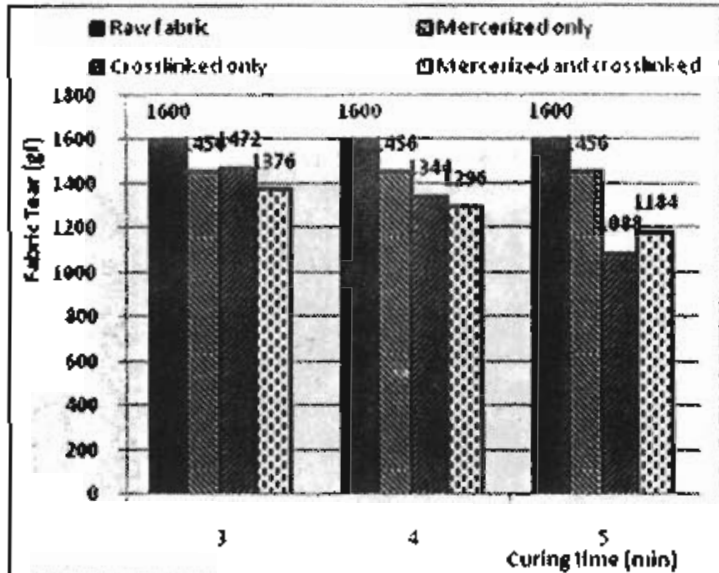

Fig. (13) Effect of mercerization and crosslinking treatments on the fabric tear of plain weave $/ / 1$ raw fabric in the weft direction.

Figure (14) shows the effect of mercerization and cross-linking on the fabric tear of warp rep weave bleached fabric in the warp direction. It is cleared that: the fabric tear increased after mercerization by a percent $21.43 \%$ then decreased after cross-linking by a percent $(16.67,14.22,23.20 \%)$ for curing times (3, 4, $5 \mathrm{~min}$ ) respectively. The best curing time for the treated fabrics is $4 \mathrm{~min}$. The fabric tear for the cross-linked sample is higher than the raw fabric by a percent $4.17 \%$.

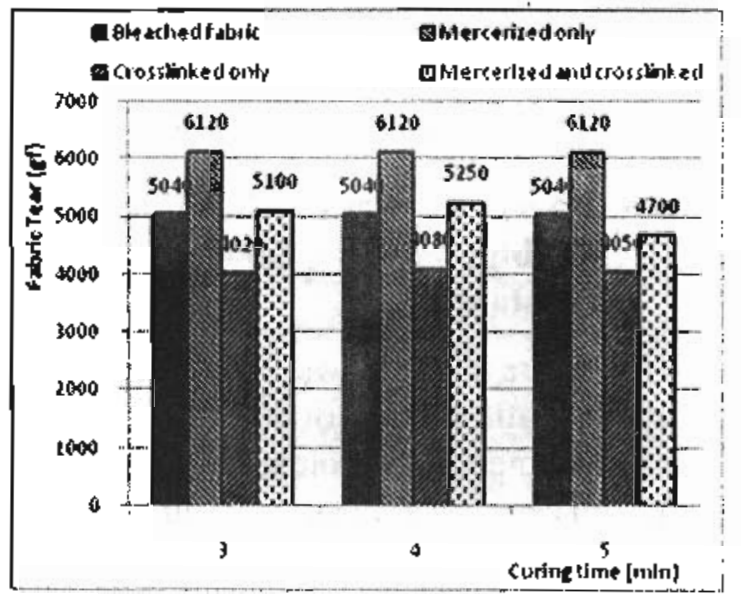

Fig. (14) Effect of mercerization and crosslinking treatments on fabric tear of warp rep

bleached fabric in the warp direction.

Figure (15) depicts the effect of mercerization and cross-linking on the fabric tear of warp rep weave bleached fabric in the weft direction. Results obtained provide that: the fabric tear increased after- mercerization by a percent $10.85 \%$ then decreased after cross-linking by a percent $(11.89,12.59,14.69 \%)$ for curing times $(3,4,5 \mathrm{~min})$ respectively. The best curing time for the treated fabrics is 3 min. The fabric tear for the cross-linked sample is lower than the raw fabric by a percent $2.33 \%$.

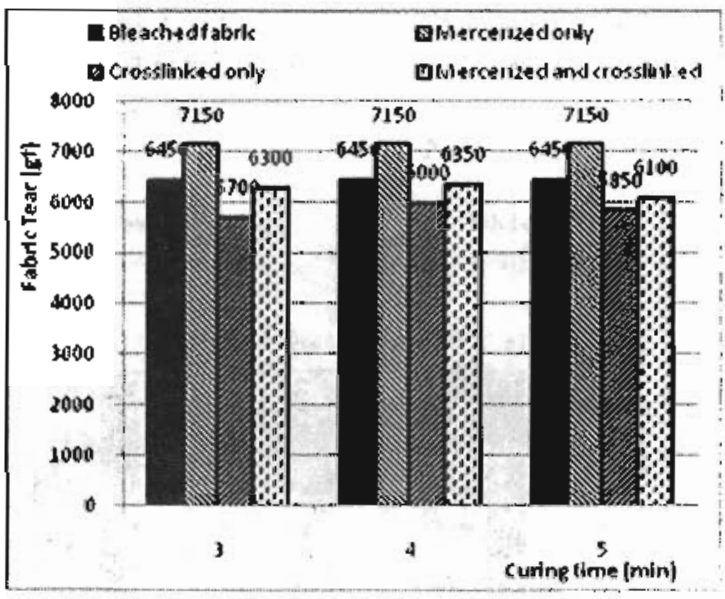

Fig. (15) Effect of mercerization and crosslinking treatments on fabric tear of warp rep bleached fabric in the weft direction.

The same action was found for twill weave $3 / 1$, as shown in figure (16) which included that: the fabric tear increased after mercerization by a percent $18.30 \%$ then decreased after cross-linking by a percent $18.70,25.20,24.40 \%$ for curing times 3 , 4, $5 \mathrm{~min}$ respectively. The best curing time for the treated fabrics is $3 \mathrm{~min}$. The fabric tear for the cross-linked sample is lower than the raw fabric by a percent $3.85 \%$.

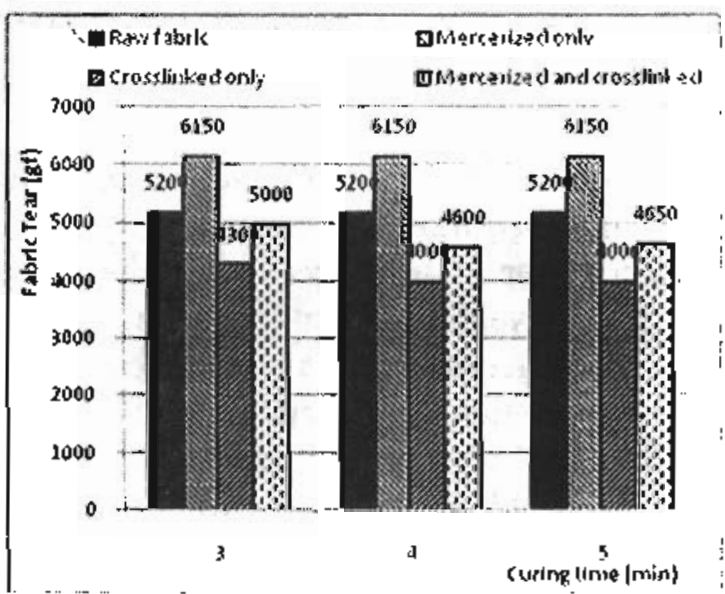

Fig. (16) Effect of mercerization and crosslinking agents on the fabric tear of twill weave row fabric in the warp direction. 
There is no clear difference for the performance of iwill weave in the weft direction as shown in figure (17), which provides these outputs: the fabric tear increased after mercerization by a percent $1.42 \%$ then decreased after cross-linking by a percent $(21.47,24.96,21.47 \%)$ for curing times $(3,4,5 \mathrm{~min})$ respectively. The best curing time for the treated fabrics is 3 min. The fabric tear for the cross-linked sample is lower than the raw fabric by a percent $20.35 \%$.

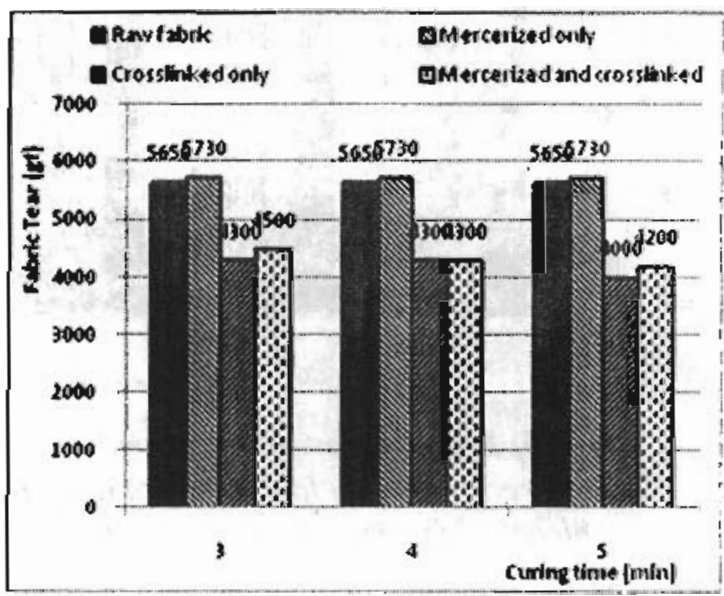

Fig. (17) Effect of mercerization and cross(inking agents on the fabric tear of twill weave row fabric in the weft direction.

Figure (18) shows that: the fabric tear increased after mercerization by a percent $16.13 \%$ then decreased after cross-linking by a percent $25.93,18.52,24.07 \%$ for curing times 3, 4, 5 min respectively. The best curing time for the treated fabrics is 4 min. The fabric tear for the cross-linked sample is lower than the raw fabric by a percent $5.38 \%$.

Similarly, figure (19) shows the effect of mercerization and cross-linking on the fabric tear of twill weave bleached fabric in the weft direction. Results obtained provide that: the fabric tear decreased after mercerization by a percent $16.51 \%$ then decreased after cross-linking by a percent $9.30,24.42,23.26 \%$ for curing times 3,4 , 5 min respectively. The best curing time for the treated fabrics is $3 \mathrm{~min}$. The fabric tear for the cross-linked sample is lower than the raw fabric by a percent $24.27 \%$.

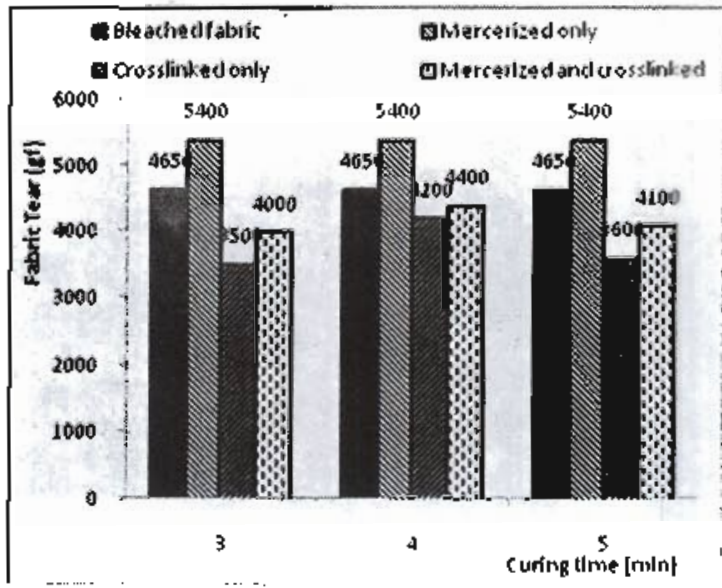

Fig. (I8) Effect of mercerization and crosslinking agents on the fabric tear of twill weave bleached fabric in the warp direction.

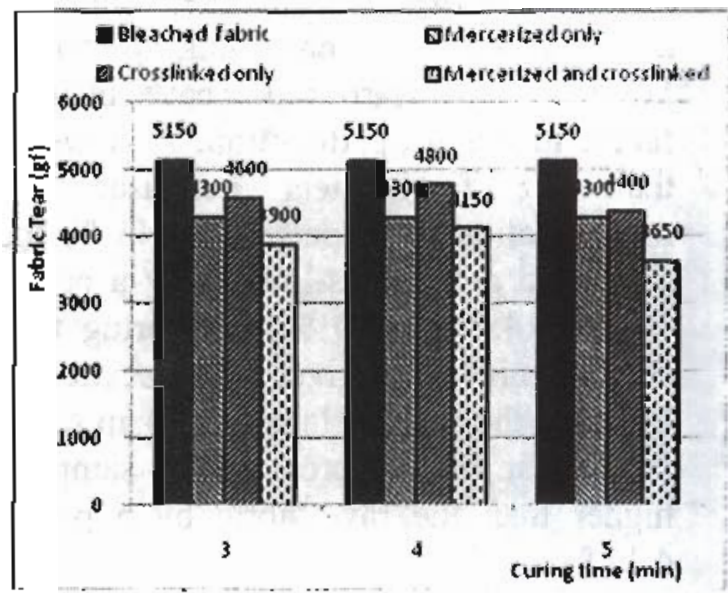

Fig. (19) Effect of mercerization and crosslinking agents on the fabric tear of twill weave bleached fabric in the weft direction.

\subsection{Effect of resin finishing (cross- linking) on fabric abrasion resistance:}

Figure (20) shows the effect of resin concentration on fabric abrasion resistance of non mercerized bleached plain weave $1 / 1$. There is a clear loss in the fabric abrasion resistance. This loss after crosslinking treatment may be due to both the cross-linking of cellulose and the degradation of cellulose caused by the catalyst. The magnitude of fabric strength loss is affected also by the temperature, time, and concentration of the catalyst. Based on the above, the following findings may be drawn: 
- At all cases, the fabric abrasion resistance for the cross-linked samples is less than the abrasion resistance for the raw samples.

- The percentage decrease in fabric abrasion resistance is approximately from $31.82 \%$ to $51.27 \%$.

- The fabric abrasion resistance increases as increasing the resin concentration from 40 to $80 \mathrm{~g} / \mathrm{lit}$ then decreases from 80 to $100 \mathrm{~g} / \mathrm{lit}$.

- The best resin concentration is 80 g/lit.

- The best curing time for the treated fabrics is $3 \mathrm{~min}$.

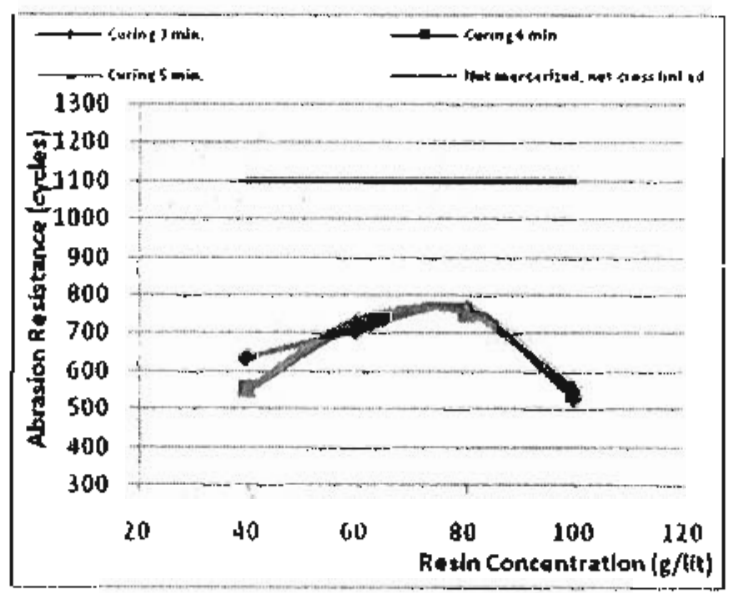

Fig. (20) Effect of resin concentration on fabric abrasion resistance of non mercerized plain weave

Figure (21) shows the effect of resin concentration on the fabric abrasion resistance of mercerized plain weave $1 / 1$. The concentration of caustic soda was 260 $\mathrm{g} / \mathrm{hit}$ and mercerizing machine speed was $30 \mathrm{~m} / \mathrm{min}$. The results obtained provide that: the percentage decrease in fabric abrasion resistance is approximately from $(29.29 \%$ to $50.19 \%)$. The fabric abrasion resistance increases as increasing the resin concentration from 40 to $80 \mathrm{~g} /$ lit then decreases from 80 to $100 \mathrm{~g} /$ lit. The best resin concentration is $80 \mathrm{~g} /$ lit. The best curing time for the treated fabrics is $3 \mathrm{~min}$.

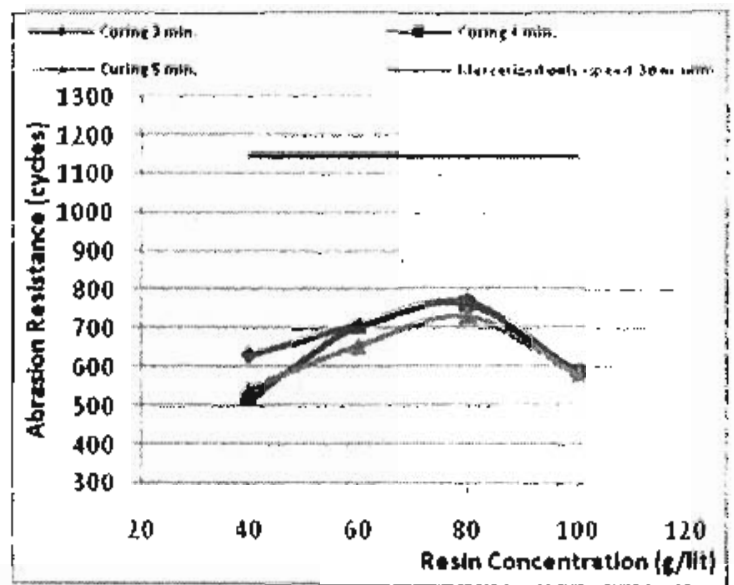

Fig. (2J) Effect of resin concentration on the fabric abrasion resistance of mercerized plain weave, mercerizing machine speed $30 \mathrm{~m} / \mathrm{min}$.

\section{5- Conclusion:}

- Performing mercerization process with high efficiency, followed by proper easy care finishing treatment results in a significant retention in mechanical properties.

- Mercerization process increases fabric strength by about 10 to $20 \%$. On the contrary, resin finish decreases the strength by about 15 to $35 \%$.

- Thus we can limit the severe strength loss by effective mercerization followed by cross-linking.

- For every fabric structure and weight per unit area there are optimum conditions of mercerization; i.e. for light fabrics the $\mathrm{NaOH}$ concentration was $260 \mathrm{~g} / \mathrm{lit}$ and the mercerizing machine speed was $30 \mathrm{~m} / \mathrm{min}$, while for heavy fabrics the $\mathrm{NaOH}$ concentration ranges from 280 to 300 $\mathrm{g} /$ lit, depending on the fabric structure. 


\section{6- References:}

[1] Grant, J. N., Andrew, F. R., Weiss, L. C. and Hassenboehler, C. B.:"Abrasion and Tensile Properties of Cross-Linked Cotton Fabrics", Textile Research Jounal, Vol. 38, No. 3, 217-225 (1968).

[2] Gunaseelan J. : "Role of silicone in resin finishing", http://www.fibre2fashion.com $(15 / 1 / 2010)$.

[3] Meyer, U., Mueller, K., and Zollinger, $\mathrm{H}$.: "Comparison of Textile Mechanical Properties of Cotton in Cross-linking with Dimethylolethyleneurea and Formaldehyde", Textile Res. J., 45, 813 (1975).

[4] Murphy, A. L., Margavio, M. F., and Welch, C. M.: "All-Cotton Durable Press Fabrics of High Strength from Slack-Mercerize", Partially Restretched Yarn, Textile Res. J., 41, 22-31 (1971).

[5] Welch, C.M.: "Improved strength and flex abrasion resistance in durable press finishing with BTCA", Textile Chemist and Colorist, 29, 21 (1997).

[6] Weilin $\mathrm{Xu}$ andYi Li.: "Cotton Fabric Strength Loss from Treatment with Polycarboxylic Acids for Durable Press Performance", Textile Research Journal, Vol. 70, No. 11, 957-961 (2000),

[7] Avinash P. Manian, Mohammad Abu Rous, K. Christian Schuster and Thomas Bechtold: "The influence of alkali pretreatments on lyocell resin finishing, resin distribution and mechanical properties", 2006 Wiley Periodicals, Inc. J Appl Polym Sci 100: 3596-3601 (2006).

[8] G. Buschle-Diller and S. H. Zeronian: "Enhancing the reactivity and strength of cotton fibers", http://www3.interscience.wiley.com/ journal (25/1/2010).

[9] Weilin Xu. : "Effect of Crosslinking Treatment on the Crystallinity, Crystallite Size, and Strength of Cotton Fibers", Textile Research Journal, Vol. 73, No. 5, $433-436$ (2003). 